\title{
Effect of atorvastatin therapy on oxidant- antioxidant status and atherosclerotic plaque formation
}

This article was published in the following Dove Press journal:

Vascular Health and Risk Management

3I May 20I I

Number of times this article has been viewed

\section{Ebru Demirel Sezer ${ }^{\prime}$ \\ Eser Yildirim Sozmen' \\ Deniz Nart ${ }^{2}$ \\ Taner Onat ${ }^{\prime}$}

'Medical Biochemistry, ${ }^{2}$ Pathology Department, Ege University School of Medicine, Izmir, Turkey
Correspondence: Ebru Demirel Sezer Ege Universitesi Tip Fakultesi, Biyokimya Anabilim Dali, Bornova, Izmir 35100, Turkey

Tel +905324636790

$\mathrm{Fax}+902323739477$

Email ebru.sezer@ege.edu.tr
Background: The aim of this study was to determine the oxidant-antioxidant status and lipid peroxidation products, as well as paraoxonase and atherosclerotic plaque formation, in a hypercholesterolemic atherosclerosis rabbit model to investigate the effects of atorvastatin in the atherosclerotic process.

Methods: Forty male New Zealand rabbits were divided into four groups, ie, a control group receiving standard pellets, a group receiving atorvastatin therapy, a hypercholesterolemic group receiving an atherogenic diet, and a group receiving both an atherogenic diet and atorvastatin.

Results: The atherogenic diet increased the levels of low-density lipoprotein (LDL) thiobarbituric acid reactive substances (1.84 vs $3.79 \mathrm{nmol} / \mathrm{mg}$ protein) and LDL-conjugated diene (147 vs $318 \mu \mathrm{mol} / \mathrm{mg}$ protein) after induction of oxidation by $\mathrm{Cu}^{2+}$, despite an increase of superoxide dismutase activity. Treatment with atorvastatin limited LDL oxidation significantly (LDL thiobarbituric acid reactive substances $2.19 \mathrm{nmol} / \mathrm{mg}$ protein, LDL-conjugated diene $222 \mu \mathrm{mol} / \mathrm{mg}$ protein). Paraoxonase, which prevents LDL oxidation and inactivates LDL-derived oxidized phospholipids, showed a pronounced decrease in the group receiving the atherogenic diet (110 U/L to $28 \mathrm{U} / \mathrm{L})$, and atorvastatin treatment increased paraoxonase activity. Histological examination of arcus aorta tissues from the hypercholesterolemic group showed abundant plaque formation surrounding and obstructing the lumen, whereas treatment with atorvastatin prevented or limited plaque formation, keeping the plaque thin and localized.

Conclusion: Atorvastatin has dramatic antiatherosclerotic effects, part of which seems to be due to the antioxidant features of the parent drug and/or its metabolites, favoring inhibition of LDL oxidation.

Keywords: atherosclerosis, atorvastatin, hypercholesterolemia, low-density lipoprotein oxidation, paraoxonase

\section{Introduction}

Atherogenesis is a chronic inflammatory process that involves a complex interplay between circulating cellular and blood elements and the cells of the arterial wall., ${ }^{1,2}$ While many factors are involved, the "oxidation hypothesis" has been a central focus in the investigation of the pathogenesis of the atherosclerotic process, suggesting that the oxidative modification of low-density lipoprotein (LDL), or other lipoproteins, is central, if not obligatory for the atherogenic process. ${ }^{3,4}$

Oxidation of LDL is a lipid peroxidation process resulting in formation of a wide range of biologically active products, including peroxides and malondialdehyde. Oxidation of LDL results in the generation of aldehydes that substitute lysine residues in the apoprotein B-100 moiety of LDL and causes apolipoprotein B-100 fragmentation. 
As a result, the particle loses its affinity for the LDL receptor and binds avidly to scavenger receptors on macrophages, resulting in foam cell formation. ${ }^{5,6}$

Advances in the management of hypercholesterolemia are primarily due to the development of the 3-hydroxy-3methylglutaryl coenzyme (HMG-Co A) reductase inhibitors, ie, the statins. ${ }^{7}$ Recently, many statins have been used for their overall antihypercholesterolemic action in patients with atherosclerosis. They are presumed to work by upregulating the LDL receptor, thereby lowering LDL cholesterol in particular. In addition to lowering cholesterol levels, statins seem to act on the formation and progression of atherosclerotic plaque through alternative mechanisms involved in progression of the disease. ${ }^{8}$ The various statins differ in their pharmacokinetics, therapeutic efficacy, drug interactions, dosage, and administration, and therefore they differ in their potential advantages and disadvantages. Reduction of lipid peroxidation may be one of the important features explaining the favorable effect of statins in preventing or reducing atherosclerosis. Even though some investigators have shown the antioxidant potential of statins in vitro, ${ }^{8}$ in vitro investigations may not be the best approach to evaluate the effects of these agents because many other relevant events may be taking place in vivo.

In this study, we examined lipid peroxidation products, ie, thiobarbituric acid reactive substances (TBARS) and LDL-conjugated diene, formed as a result of oxidative stress generated in a hypercholesterolemic atherosclerosis model in rabbits. The antioxidant activity of defensive enzymes, including superoxide dismutase, catalase, and paraoxonase, was also investigated to determine oxidative status. The effects of atorvastatin, a potent HMG-Co A reductase inhibitor, with the longest half-life of its group, was evaluated for its influence on lipid profiles, lipid peroxidation, and the antioxidant system, as well as its impact on paraoxonase activity. In addition, atherosclerotic plaque formation and the outcome of atorvastatin treatment was assessed histopathologically.

\section{Methods}

\section{Animal model}

Forty male New Zealand rabbits weighing 2.5-3.5 kg were used for the hypercholesterolemic animal model. The study protocol was reviewed and approved by the ethics committee of the Ege University Medical School. All the animals were housed in individual cages and were quarantined for 7 days prior to the study, and received standard pellets (15\% protein, $2.5 \%$ lipid, $15 \%$ cellulose, $14 \%$ clay, $13 \%$ water) during this time. The rabbits were then divided into four groups: Group 1, which received standard pellets of $100 \mathrm{~g} / \mathrm{kg} /$ day for 15 weeks (controls, $n=11$ ); Group 2, which received standard pellets for 15 weeks, with atorvastatin $5 \mathrm{mg} / \mathrm{kg} /$ day added from week 7 and continued until the end of week 15 (atorvastatin group, $\mathrm{n}=10$ ); Group 3, which received an atherogenic diet (100 g/kg/day, 2\% cholesterol, $1.5 \%$ butter added to standard pellets) for 15 weeks (atherogenic diet group, $\mathrm{n}=9$ ); and Group 4, which received an atherogenic diet with atorvastatin added from week 7 until the end of week 15 (atherogenic diet + atorvastatin group, $\mathrm{n}=10$ ). Blood samples were collected from the ear veins of all rabbits at baseline, at week 7 just before starting atorvastatin treatment, and at the end of the study at week 15 . All blood samples were obtained after an overnight fast, and all serum and plasma was immediately separated. All animals were sacrificed using an overdose of pentobarbital. The study and its design were approved by the local ethics and research committee of Ege University, Faculty of Medicine.

\section{Serum analysis}

Serum samples were stored at $-80^{\circ} \mathrm{C}$ until analysis. Serum paraoxonase activity was measured using the synthetic substrate, paraoxon (diethyl- $\rho$-nitrophenyl phosphate). Paraoxonase activity towards paraoxon was assessed by measuring liberation of $\rho$-nitrophenol. The $\rho$-nitrophenol production rate at $405 \mathrm{~nm}$ was recorded for 2.5 minutes at 15 -second intervals. Other serum parameters, ie, total cholesterol, triglyceride, high-density lipoprotein (HDL) cholesterol and LDL cholesterol, were determined by routine commercial kits (Randox Laboratories Ltd, County Antrim, Ireland).

\section{Erythrocyte analysis}

After separation of plasma, the packed erythrocytes were washed twice with $9 \mathrm{~g} / \mathrm{L} \mathrm{NaCl}$ solution and hemolyzed with icecold water $(1 / 5, \mathrm{v} / \mathrm{v})$. Superoxide dismutase activity and catalase activity were determined immediately in the hemolysates. Hemoglobin values were measured by Drabkin's method. ${ }^{9}$

Superoxide dismutase activity was measured spectrophotometrically based on the inhibition of epinephrine autooxidation by superoxide dismutase at $480 \mathrm{~nm}$ as described by Sozmen et al, using a Shimadzu UV-120 spectrophotometer (Kyoto, Japan). The assay was calibrated using purified superoxide dismutase, and 1 unit of enzyme was defined as the amount that inhibits $50 \%$ of auto-oxidation of epinephrine. ${ }^{10}$

Catalase activity was determined as described by Aebi. ${ }^{11}$ The degradation of hydrogen peroxide $\left(\mathrm{H}_{2} \mathrm{O}_{2}\right)$ by the catalase enzyme was recorded spectrophotometrically 
at $240 \mathrm{~nm}$. One unit of catalase was defined as the amount of enzyme that decomposes $1 \mu \mathrm{mol} \mathrm{H}_{2} \mathrm{O}_{2} /$ minute under specific conditions.

For measurement of TBARS levels, thiobarbituric acid $0.12 \mathrm{M}$ in trichloroacetic acid $15 \%$ and $\mathrm{HCl} 1 \%$ was added to the hemolysates and boiled at $100^{\circ} \mathrm{C}$ for 20 minutes. After centrifugation at $2000 \mathrm{rpm}$ for 10 minutes, absorbance of the supernatant at $532 \mathrm{~nm}$ was measured spectrophotometrically. The results were calculated as nmol/mL with respect to standards prepared with 1,1,3,3-tetraetoxypropane. The results are given as nmol/g of hemoglobin.

\section{LDL isolation and in vitro oxidation}

Plasma samples were incubated at room temperature for 30 minutes with a commercial precipitant reagent (Merck, Darmstadt, Germany), as suggested by Taus et al. ${ }^{12}$ After centrifugation at $1600 \mathrm{~g}$ for 10 minutes, LDL samples were solubilized using sodium hydroxide $0.15 \mathrm{M}$. LDL oxidation was assessed by TBARS and LDL-conjugated diene levels in LDL samples containing $200 \mu \mathrm{g}$ of protein. LDL oxidation was monitored at $234 \mathrm{~nm}$ with a Shimadzu UV-120 spectrophotometer, and the calculations were performed using an extinction coefficient of $29,500 \mathrm{~L} / \mathrm{mol} / \mathrm{cm}$.

In vitro oxidation of LDL was induced by incubating the isolated lipoproteins with copper sulfate $\left(\mathrm{CuSO}_{4}\right) 5 \mu \mathrm{M}$, and LDL-conjugated diene formation was analyzed by monitoring the absorbance change at $234 \mathrm{~nm}$ over 3 hours at 5-minute intervals. The peak of diene conjugation was observed and assessed at minute 110 after stimulation of in vitro oxidation of LDL (sLDL diene) with $\mathrm{CuSO}_{4}$. TBARS levels (sLDL TBARS) were also determined at this point. Protein measurements were performed according to Lowry's method. ${ }^{13}$

\section{Tissue analysis}

Arcus aortic tissues were removed and washed in saline. For the biochemical assays, aortic tissues were homogenized in ice-cold phosphate buffer and centrifuged at $2000 \mathrm{~g}$ for 10 minutes. Superoxide dismutase and catalase assays were done, as described for the hemolysate measurements.

Malondialdehyde levels were measured using a commercial kit (LPO-586; Oxis Research, Beverly Hills, CA). The assay is based on a chromogenic reaction, ie, N-methyl2-phenylindole with malondialdehyde. The results were calculated as $\mathrm{nmol} / \mathrm{g}$ protein with respect to the calibration curve prepared with 1,1,3,3-tetraethoxypropane.

The arcus aortic tissues were fixed with formaldehyde $10 \%$ for histopathological examination. After fixation, the arteries were embedded in paraffin and cross-sectioned into slices of 4-5 $\mu \mathrm{m}$ thickness at $5 \mathrm{~mm}$ intervals. The crosssections of aortic tissue were stained with hematoxylin and eosin, and examined using an Olympus BH-2 light microscope (Tokyo, Japan).

\section{Statistical analysis}

Statistical analyses were performed using the statistical SPSS package program for Windows, (v 11; SPSS Inc, Chicago, IL). Comparisons of parameters between the different groups were done using the nonparametric Mann-Whitney U test. Statistical evaluations within the groups were done using the Wilcoxon signed-rank test. $P<0.05$ was considered to indicate a statistically significant difference for both tests.

\section{Results \\ Lipid profile}

As expected, the atherogenic diet caused a pronounced increase in all lipid fractions $(P<0.01$, Table 1$)$. Atorvastatin treatment achieved a significant $32.7 \%$ decrease $(P<0.01)$ in total cholesterol, a $25.5 \%$ decrease $(P<0.01)$ in LDL cholesterol, and a $14 \%$ decrease in HDL cholesterol $(P<0.01)$ in Group 4. In our model, treatment with atorvastatin did not cause a significant change in triglyceride levels.

\section{Oxidative status of erythrocytes}

Analysis at week 7 showed that the atherogenic diet caused a significant increase $(P<0.01)$ in superoxide dismutase and catalase activity in Group 3 and Group 4 compared with basal levels (Table 2). The atherogenic diet for 7 weeks doubled the TBARS levels $(P<0.01)$ in Group 3 and Group 4. While treatment with atorvastatin led to a significant decrease in superoxide dismutase activity $(P<0.05)$ and TBARS levels $(P<0.05)$, it had no significant effect on catalase activity in Group 4. Comparison of superoxide dismutase levels in the second and final blood samples indicated that the superoxide dismutase levels in Group 3 (atherogenic diet without treatment) continued to increase in the second half of the experiment but the increase was not statistically significant. Even though catalase activity was modified by atorvastatin treatment, the change was not statistically significant, in contrast with superoxide dismutase activity (Table 2).

\section{LDL oxidation and paraoxonase}

TBARS and LDL-conjugated diene levels are shown in Figure 1. Basal levels were measured at 0 minutes (bLDL TBARS and bLDL diene) before induction of $\mathrm{Cu}^{2+}$ oxidation, and stimulated levels were measured at minute 110 (sLDL TBARS and sLDL diene) after induction of oxidation. 
Table I Serum total cholesterol, LDL cholesterol, HDL cholesterol, and triglyceride levels throughout the experiment

\begin{tabular}{|c|c|c|c|c|}
\hline $\begin{array}{l}\text { Median/percentile } \\
(10 \%-90 \%)\end{array}$ & $\begin{array}{l}\text { Group I } \\
\text { Normal diet } \\
(n=I I)\end{array}$ & $\begin{array}{l}\text { Group } 2 \\
\text { Normal diet }+ \\
\text { atorvastatin }(n=10)\end{array}$ & $\begin{array}{l}\text { Group } 3 \\
\text { Hypercholesterolemic } \\
\operatorname{diet}(n=9)\end{array}$ & $\begin{array}{l}\text { Group } 4 \\
\text { Hypercholesterolemic } \\
\text { diet }+ \text { atorvastatin }(n=10)\end{array}$ \\
\hline \multicolumn{5}{|l|}{$\overline{T C}(\mathrm{mg} / \mathrm{dL})$} \\
\hline 0 & $110(9 \mid-137)$ & $116(90-|4|)$ & II 6 (72-|44) & II3 (89-I49) \\
\hline Week 7 & II4 (87-|4I) & II (78-133) & $|84|^{\mathrm{a}, \mathrm{b}, \mathrm{x}}(|||| \mid-2599)$ & $1687^{\mathrm{a}, \mathrm{b}, \mathrm{x}}(|||| 2-2 \mid 42)$ \\
\hline Week I5 & III (89-137) & $92(67-105)$ & $2015^{\mathrm{a}, \mathrm{b}, \mathrm{x}}(1097-29 \mid 3)$ & $1 \mid 35^{\mathrm{a}, \mathrm{b}, \mathrm{c}, \mathrm{x}, \mathrm{y}}(975-1365)$ \\
\hline \multicolumn{5}{|l|}{ LDL (mg/dL) } \\
\hline 0 & $70(5 \mid-102)$ & $77(36-86)$ & $72(25-100)$ & $56(43-97)$ \\
\hline Week 7 & 78 (58-99) & 73 (36-97) & $1658^{\mathrm{a}, \mathrm{b}, \mathrm{x}}(1002-2420)$ & $15 \mid 7^{\mathrm{a}, \mathrm{b}, \mathrm{x}}(955-1936)$ \\
\hline Week I5 & $63(46-95)$ & $49^{\phi, y}(21-82)$ & $1807^{\mathrm{a}, \mathrm{b}, \mathrm{x}}(857-2658)$ & || $\mid 30^{\mathrm{a}, \mathrm{b}, \mathrm{z}, \mathrm{x}, \gamma}(739-\mid 507)$ \\
\hline \multicolumn{5}{|l|}{ HDL (mg/dL) } \\
\hline 0 & $19(|4-3|)$ & $27(|5-3|)$ & $21(14-27)$ & $25(14-33)$ \\
\hline Week 7 & $18(11-37)$ & $21(12-30)$ & $|2|^{\mathrm{a}, \mathrm{b}, \mathrm{x}}(28-2 \mid 2)$ & $\left.12\right|^{a, b, x}(|| 3-188)$ \\
\hline Week I5 & $20(13-35)$ & $20 \times(11-25)$ & $132^{\mathrm{a}, \mathrm{b}, \mathrm{x}}(82-2 \mid 7)$ & $104^{a, b, x, y}(9|-| 8 \mid)$ \\
\hline \multicolumn{5}{|c|}{ Triglycerides (mg/dL) } \\
\hline 0 & $105(20-|7|)$ & $98(47-228)$ & $104(94-166)$ & $109(97-159)$ \\
\hline Week 7 & $112(64-194)$ & 116 (49-222) & $\left.26\right|^{a, b, x}(|| 3-482)$ & $357^{a, b, x}(193-432)$ \\
\hline Week 15 & $124(7 \mid-282)$ & $67(46-285)$ & $287^{\mathrm{a}, \mathrm{b}, \mathrm{x}}(191-450)$ & $362^{\mathrm{a}, \mathrm{b}}(24 \mathrm{I}-706)$ \\
\hline
\end{tabular}

Notes: a $p<0.01$, Mann-Whitney U test, vs Group I (controls); ${ }^{p} p<0.01$, Mann-Whitney U test vs Group 2; $c p<0.01$, $\varepsilon p<0,05$; Mann-Whitney $U$ test, comparison between Group 3 and Group 4 are evaluated; $\times P<0.0$ I; ${ }^{\oplus P}<0.05$, Wilcoxon signed-rank test, vs first blood samples within the same group; $>P<0.0$ I; $>P<0.05$, Wilcoxon signed-rank test vs week 7 and week 15 blood samples.

Abbreviations: LDL, low-density cholesterol; HDL, high-density cholesterol; TC, total cholesterol.

The baseline blood samples showed no difference between the groups for LDL diene and TBARS levels. The atherogenic diet (Group 3 and Group 4) caused a pronounced increase in both basal and $\mathrm{Cu}^{2+}$-stimulated LDL-conjugated diene levels $(P<0.01$, Figure 1A). bLDL TBARS levels after 7 weeks of the atherogenic diet showed no significant difference, but $\mathrm{Cu}^{2+}$-stimulated sLDL TBARS levels at 110 minutes for both atherogenic diet groups were significantly higher than for the normal diet groups $(P<0.01$, Figure 1B).
Eight weeks of treatment with atorvastatin significantly decreased both sLDL TBARS levels $(25.3 \%, P<0.05)$ and sLDL-conjugated diene levels $(25.5 \%, P<0.01)$ in Group 4 in comparison with the atherogenic diet group not receiving atorvastatin treatment (Group 3). There was a significant difference between the results for the atherogenic diet groups with and without atorvastatin treatment (Group 3 and Group 4, respectively) for LDL TBARS $(P<0.01)$ and LDLconjugated diene levels $(P<0.05$, Figures 1A and 1B).

Table 2 Erythrocyte, superoxide dismutase, and catalase activity, and TBARS levels

\begin{tabular}{|c|c|c|c|c|}
\hline $\begin{array}{l}\text { Median/percentiles } \\
(10 \%-90 \%)\end{array}$ & $\begin{array}{l}\text { Group I } \\
\text { Normal diet } \\
(n=I I)\end{array}$ & $\begin{array}{l}\text { Group } 2 \\
\text { Normal diet }+ \\
\text { atorvastatin }(n=10)\end{array}$ & $\begin{array}{l}\text { Group } 3 \\
\text { Hypercholesterolemic } \\
\text { diet }(n=9)\end{array}$ & $\begin{array}{l}\text { Group } 4 \\
\text { Hypercholesterolemic } \\
\text { diet }+ \text { atorvastatin }(n=10)\end{array}$ \\
\hline \multicolumn{5}{|l|}{ eSOD (U/gHb) } \\
\hline Start & 3333 (1965-5039) & $3064(1537-4610)$ & 2835 (I727-5423) & $2984(1274-6393)$ \\
\hline Week 7 & $3196(2734-446 I)$ & $2997(2053-4198)$ & $6973^{\mathrm{a}, \mathrm{b}, \mathrm{d}}(5478-8392)$ & $7237^{\mathrm{a}, \mathrm{b}, \mathrm{x}}(40 \mathrm{II}-10,259)$ \\
\hline Week I5 & 3655 (2919-4885) & $3188(1767-3950)$ & $\left.810\right|^{a, b, d}(4706-13,084)$ & $5620^{a, b, \varepsilon, \times, \gamma \gamma}(3964-9325)$ \\
\hline \multicolumn{5}{|l|}{ eCAT (U/g Hb) } \\
\hline Start & $9013(8258-12,015)$ & $9106(6585-12,637)$ & $9307(7023-10,919)$ & $9342(882|-10,8| 5)$ \\
\hline Week 7 & $9335(8478-10,821)$ & $9603(7690-12,872)$ & $10043^{\alpha, \phi}(8239-\mid 8,888)$ & $12245^{\alpha, \phi}(7202-20,126)$ \\
\hline Week I5 & $9232(8306-11,045)$ & $9521(8336-11,776)$ & $10532^{\alpha, \phi}(9227-17,192)$ & $1053 \mid(6523-\mid 4,025)$ \\
\hline \multicolumn{5}{|l|}{ eTBARS (nmol/g Hb) } \\
\hline Start & $4210(2948-48 I I)$ & $4365(3444-4903)$ & 3994 (3348-4973) & $4537(3180-5715)$ \\
\hline Week 7 & 4110 (3338-5457) & $4363(4076-5174)$ & $7463^{\mathrm{a}, \mathrm{b}, \mathrm{d}}(65 \mathrm{I}-9457)$ & $84 \mid 5^{\mathrm{a}, \mathrm{b}, \mathrm{x}}(4607-12,748)$ \\
\hline Week I5 & $4283(29 \mid 5-5083)$ & 4429 (4039-5 I47) & $7035^{a, b, d}(6054-14,5 \mid 8)$ & $6688^{\mathrm{a}, \mathrm{b}, \mathrm{x}, \gamma}(4083-10,155)$ \\
\hline
\end{tabular}

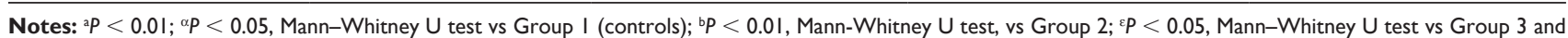
Group 4; ${ }^{d} P<0.01$; ${ }^{\circledR} P<0.05$; Wilcoxon signed-rank test vs first blood samples, within the same group; ${ }^{\Upsilon P}<0.05$; Wilcoxon signed-rank test vs second and third blood samples.

Abbreviations: e, erythrocyte; Hb, hemoglobin; CAT, catalase; SOD, superoxide dismutase; TBARS, thiobarbituric acid reactive substances. 
A

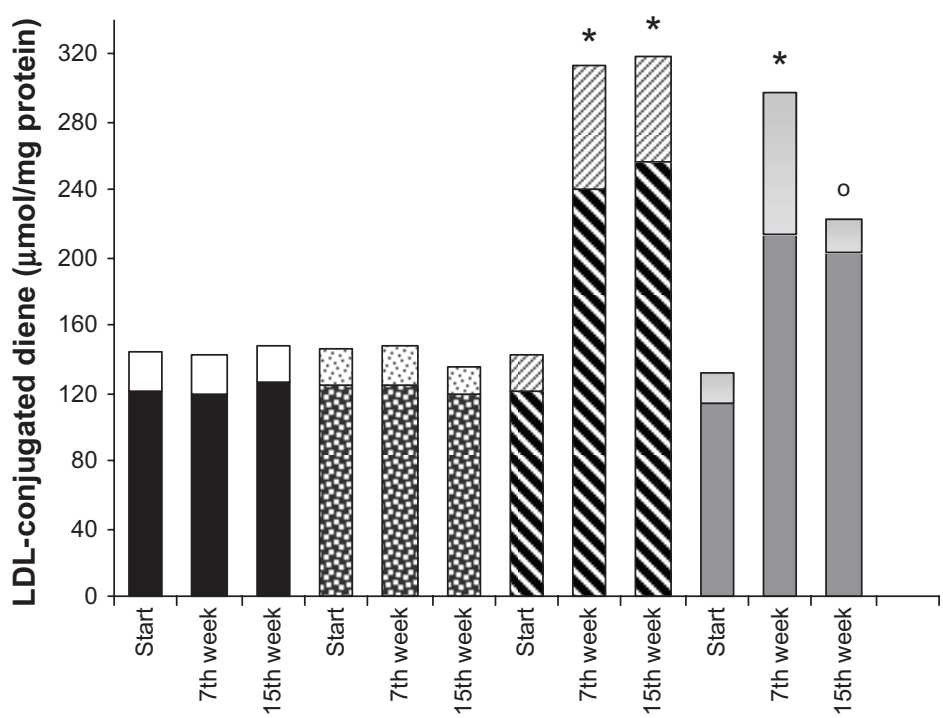

B

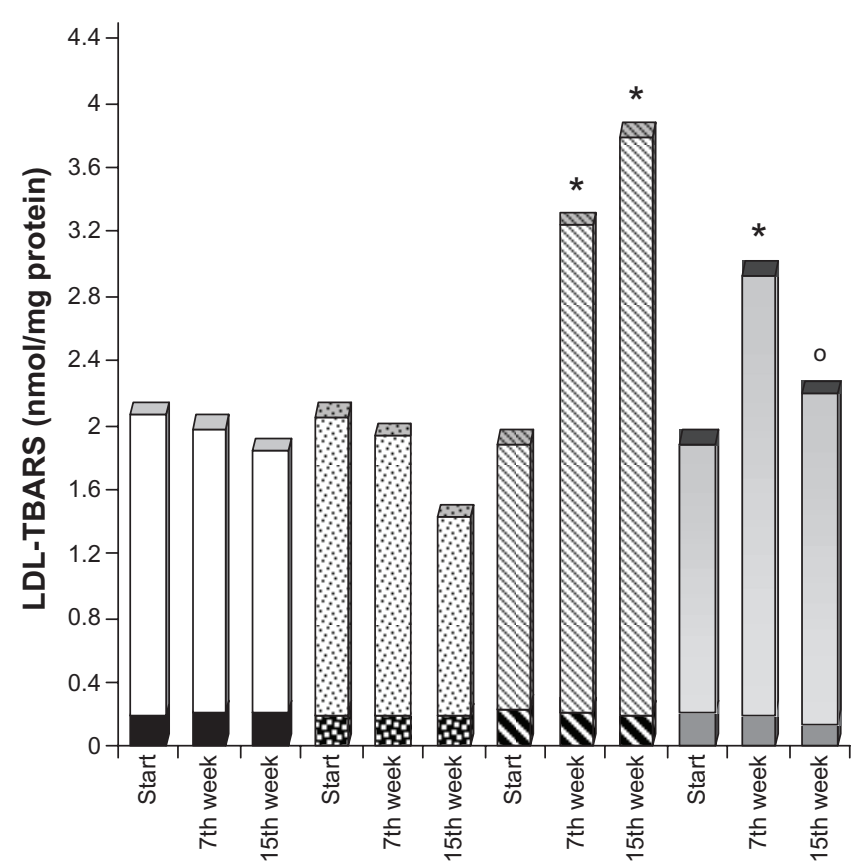

Group III:

Hypercholesterolemic diet $0^{\prime} 110^{\prime}$

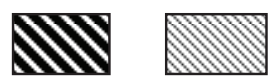

\section{Group VI :}

Hypercholesterolemic diet + atorvastatin $0^{\prime} 110^{\prime}$
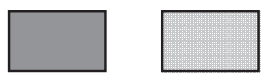

Figure I A) 0 minutes (basal) and I 10 minutes (after induction of oxidation with $\mathrm{Cu}^{2+}$ ) values of LDL-conjugated diene and B) LDL TBARS levels of all groups by the time of the experiment.

Notes: " $\mathrm{P}<0.0 \mathrm{I}$, Mann-Whitney $\mathrm{U}$ test vs Group I (controls); ${ }^{\circ} \mathrm{P}<0.01$, Wilcoxon signed-rank test; comparison of values before and after atorvastatin treatment within the group.

Abbreviations: LDL, low-density lipoprotein; TBARS, thiobarbituric acid reactive substances.

As shown in Figure 2, paraoxonase activity in all groups showed no difference at baseline. In the second blood samples taken at week 7, paraoxonase activity in the atherogenic diet groups (Group 3 and Group 4) was significantly lower than in the normal diet groups (Group 1 and Group 2, $P<0.01$ ). Evaluation within the same groups showed that the atherogenic diet decreased paraoxonase activity significantly $(P<0.01)$. Atorvastatin treatment caused an increase in paraoxonase activity in Group $4(P<0.01)$, but this increase was not statistically significant in comparison with untreated hypercholesterolemic rabbits in Group 3.

\section{Oxidant-antioxidant status in aortic tissue}

Superoxide dismutase activity in the arcus aortic tissues from the atherogenic diet group was significantly higher than in the control group $(P<0.01$, Figure 3$)$. Superoxide dismutase 


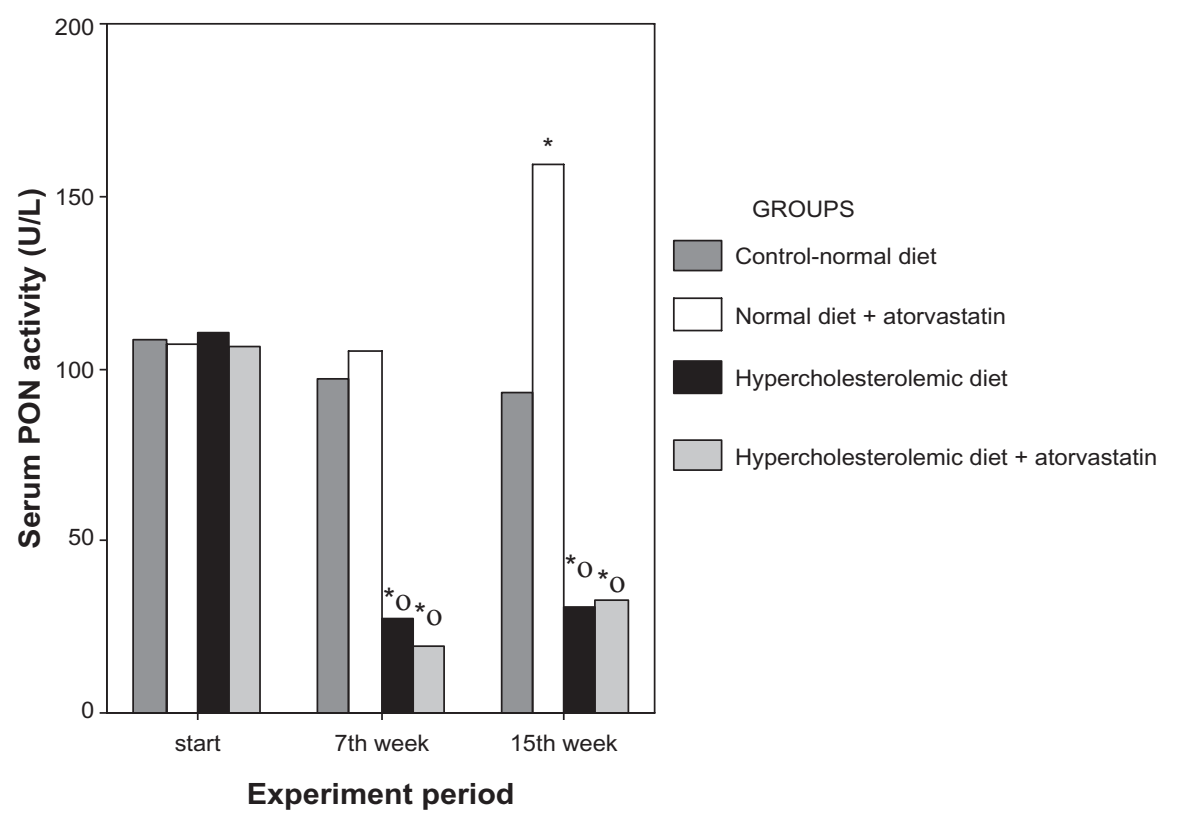

Figure 2 Serum paraoxonase activities in the first blood samples at the beginning of the experiment, the second blood samples taken at the end of week 7 after application of different diet protocols specific to each group, and the third blood samples taken after atorvastatin treatment.

Notes: $* P<0.0$ I, Mann-Whitney $U$ test vs Group I (controls); ${ }^{\circ} P<0.0$ I, Wilcoxon signed-rank test vs baseline.

Abbreviation: PON, paraoxonase.

activity in Group 4 was as low as in the control group. Superoxide dismutase and catalase activity in aortic tissue did not show any significant difference between the treatment groups. Malondialdehyde levels in the aortic tissues of the atherogenic diet group was significantly higher than in the control group $(P<0.01)$, and atorvastatin treatment lowered malondialdehyde levels to basal values (Figure 3).

\section{Histopathological examination of arcus aortic tissue}

Histological sections of arcus aortic tissue were stained with hematoxylin and eosin and examined microscopically. The microscopic images of the arcus aortic sections of the normal diet groups appeared normal, with organized intimal surfaces (Figure 4A). In the microscopic images obtained for arcus aortic sections from the hypercholesterolemic group without any treatment (Group 3), thick atherosclerotic plaques were observed surrounding the intima, and the arterial lumina were visibly obstructed by these plaques. Leukocyte infiltrations were noticeable in the intima of these specimens (Figures 4B and 4C). In Group 4, which received atorvastatin treatment, it was observed that plaque formation was totally or partially repressed, and significantly localized (Figures 4D, 4E, and 4F).

\section{Discussion}

Even though atherosclerosis is a complex, progressive, and multifactorial disease, nowadays there is no doubt that elevated plasma cholesterol levels play a dominant role in its pathogenesis. HMG-CoA reductase inhibitors, ie, statins, are widely prescribed in many countries to lower cholesterol levels in patients at risk. ${ }^{14}$ In this study, we investigated the effect of atorvastatin on the oxidant-antioxidant status of LDL cholesterol and erythrocytes, as well as in arcus aortic tissue.

In the animal model used, an atherogenic diet severely increased cholesterol levels (Table 1). Plasma total cholesterol and LDL cholesterol levels reached about 20 times the initial values, consistent with the results of another study reported by Bustos et al. ${ }^{15}$ The increase in triglyceride levels may have been associated with the addition of butter to the atherogenic diet.

Besides being a potent $\mathrm{HMG}-\mathrm{CoA}$ reductase inhibitor, atorvastatin also has the longest half-life among the available statins, which contributes to its high efficacy. In view of this and conflicting reports about the antioxidant characteristics of the drug, atorvastatin was chosen from the available statins for this study. The dose of atorvastatin used ( $5 \mathrm{mg} / \mathrm{kg} /$ day) was decided on the basis of previous experiments using 1 , 2.5 , and $10 \mathrm{mg} / \mathrm{kg} /$ day. $^{15}$

It must be emphasized that, in contrast with other studies, we did not start atorvastatin treatment at the beginning of the experiment, but started it after 7 weeks of the atherogenic diet, in order to mimic conditions of human atherosclerosis, where statins are used in most cases after atherogenesis is established. Most studies in humans are performed after the 
A

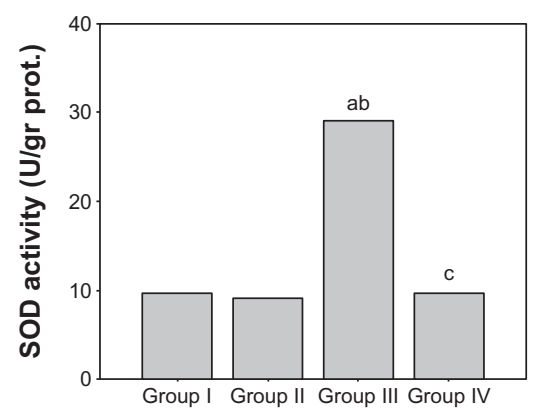

C

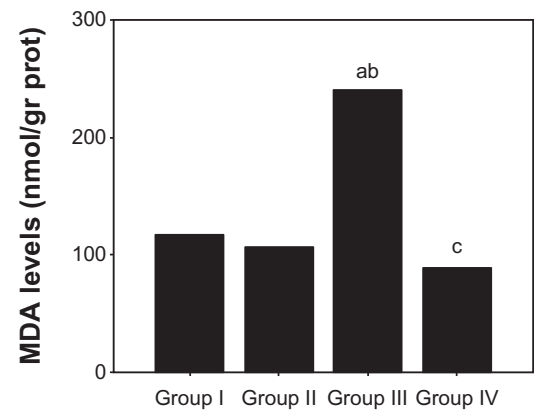

\section{B}

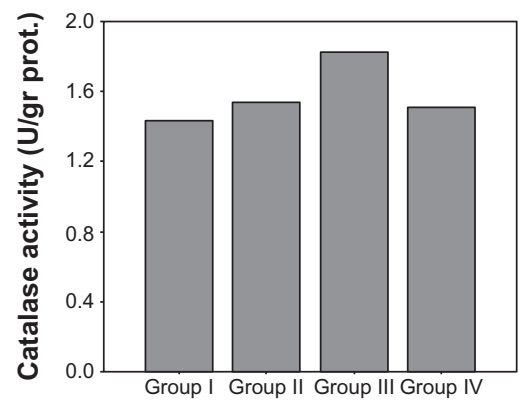

Figure 3 A) Superoxide dismutase activity, B) catalase activity, C) malondialdehyde levels in the arcus aorta tissue of different groups of subjects.

Notes: ${ }^{a} P<0.0$ I, by Mann-Whitney $U$ test vs Group I (control); ${ }^{b} P<0.0$ I, by Mann-Whitney $U$ test vs Group 2 ; ${ }^{c} p<0.0$ I by Mann-Whitney $U$ test vs Group 3 and Group 4 (effect of atorvastatin treatment).

Abbreviations: SOD, superoxide dismutase; MDA, malondialdehyde.

onset of clinical signs when the disease is well advanced. In this respect, animal models are more convenient to use because they allow study of the initiation and progression of the preclinical stages of atherosclerosis in a more controlled setting within a shorter period of time. As expected, atorvastatin achieved a $25 \%$ decrease in LDL cholesterol levels, consistent with previous studies. ${ }^{15-17}$

LDL levels in the atherogenic diet group were higher than in the control group in spite of treatment with atorvastatin, probably due to the excessive amount of cholesterol added to the diet. However, this gave us the opportunity to examine and compare the beneficial effects of atorvastatin additional to lowering of cholesterol levels.

Erythrocytes are a very appropriate medium via which cholesterol can exert a pro-oxidant action due to the potential for free radical generation. Therefore, in this study, oxidant status was studied in erythrocytes ${ }^{18,19}$ as well as in LDL fractions. Our results show that an atherogenic diet caused a prominent increase in superoxide dismutase and catalase antioxidant activity and also in TBARS levels (Table 2). The increase in superoxide dismutase activity represents an important physiological adaptation counteracting the increase in oxidative stress. ${ }^{19}$ The enhanced levels of TBARS are also an indicator of the oxidant stress induced by hypercholesterolemia. In this study, the increase in TBARS levels in spite of enhanced superoxide dismutase activity suggests that the elevation in superoxide dismutase activity was inadequate for complete prevention of lipid peroxidation in the hypercholesterolemic group. The significant decrease in superoxide dismutase activity in erythrocytes and changes in TBARS levels after 8 weeks of atorvastatin treatment, indicate the antioxidant effect of the drug, in support of previous studies. ${ }^{20,21}$

Wassmann et $\mathrm{a}^{22}$ reported increased catalase protein expression and enzyme activity following upregulation of catalase mRNA, with no significant alteration in mRNA expression of superoxide dismutase in vascular smooth muscle cells in vitro. In the same study, while atorvastatin did not have any significant effect on vascular mRNA expression of superoxide dismutase, vascular catalase mRNA expression was increased in the aortic tissue of hypertensive rats treated with atorvastatin in comparison with controls. In the present study, the changes in superoxide dismutase and catalase activity coincide with the in vivo results of the study reported by Wassmann et al. The more distinctive changes in superoxide dismutase activity than in catalase activity may be due to the different animal models used. 
A

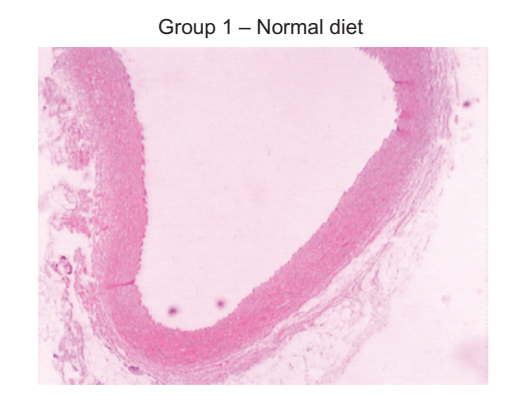

D

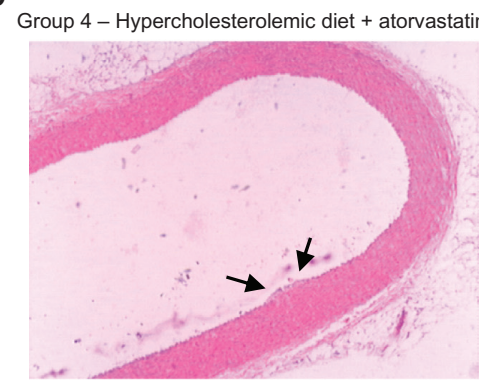

B

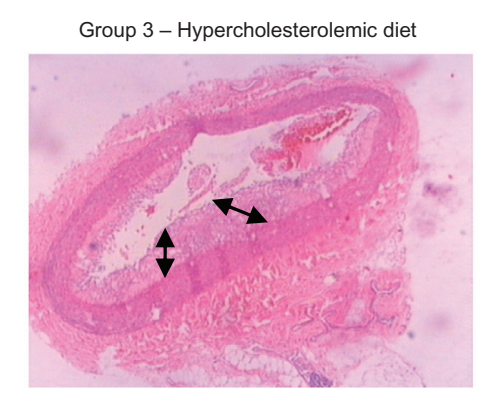

E

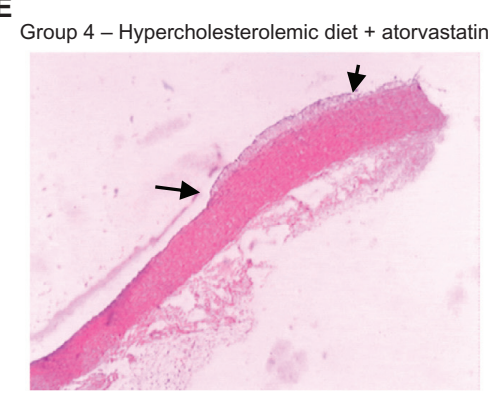

C

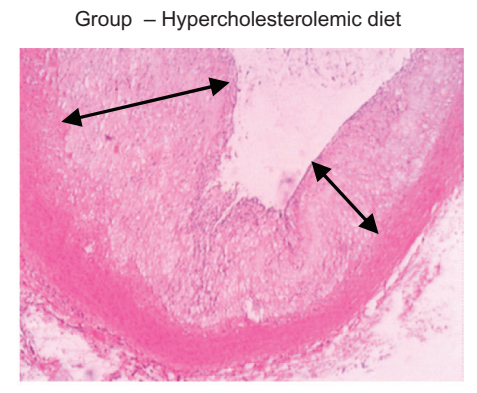

$F$

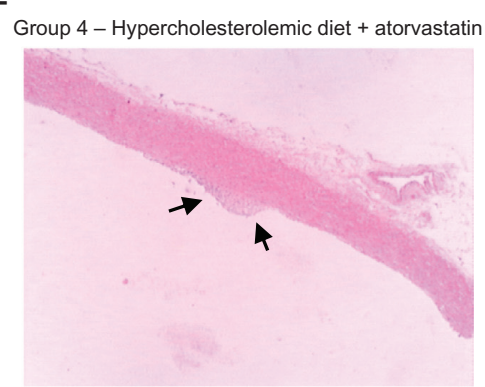

Figure 4 Histological images of arcus aorta tissues of different groups. A) Group I, normal diet, normal epithelial and intimal lamina; B, C) Group 3, hypercholesterolemic diet and with huge atherosclerotic plaques surrounding the lumen; D-F) Group 4, hypercholesterolemic diet and atorvastatin treatment, with thin and limited atherosclerotic plaque formation.

Atorvastatin and its metabolites formed in in vivo circumstances may prevent enhancement of the hydroxyl and peroxyl radicals generated by hypercholesterolemia, probably via their radical scavenging, metal-chelating capacity, and the attenuating effect on output of superoxide anions.

In this study, LDL TBARS and LDL-conjugated diene levels were measured at baseline and after induction of oxidation using $\mathrm{Cu}^{2+}$ to evaluate the oxidation status of LDL. The significant increase in LDL TBARS and LDL-conjugated diene levels in the hypercholesterolemic rabbits represents the effect of hypercholesterolemia on the oxidative modification of LDL, probably via increased susceptibility to oxidation. ${ }^{2}$

The results of this study demonstrate the success of atorvastatin therapy in alleviating the production of LDL TBARS and LDL-conjugated diene. The oxidatively modified lipids and their degradation products are believed to have proinflammatory, immunogenic, and cytotoxic properties which contribute to both the initiation and progression of atherosclerotic lesions. It is reported that products of oxidatively modified LDL contribute to recruitment of monocytes and $\mathrm{T}$ cells, directly or indirectly, via induction of chemokines and endothelial cell adhesion molecules. ${ }^{2}$ The present study supports this hypothesis, with histopathological examination showing atherosclerotic plaque formation and nearly $50 \%$ luminal narrowing (Figures 1A and 1B) in aortic tissue from the nontreated atherogenic diet group.
There is no doubt that statins have a positive effect on regulation of total cholesterol and LDL cholesterol levels. Some authors have suggested that inhibition of LDL oxidation by statins may be independent of any lipid-lowering effects. ${ }^{23}$ According to earlier studies, statins were assumed to reduce susceptibility of LDL to in vitro oxidation. ${ }^{24}$ It has been suggested that the inhibitory effect of statins on LDL oxidation may result from enhanced removal from plasma of "aged" LDL, which is more prone to oxidation than newly synthesized LDL. This effect could be due to statin-induced stimulation of LDL receptor activity in liver cells and to the inhibition of very low-density LDL (VLDL) and LDL production in the liver. ${ }^{25}$ However, a few studies have reported that, with the exception of fluvastatin, none of the parent forms of the hypolipidemic drugs studied demonstrated a direct inhibitory antioxidant effect on LDL oxidation. ${ }^{26}$

Singh et al reported that atorvastatin therapy had a doseresponse effect with regard to decreasing oxidized LDL. They also reported other pleiotropic effects of the drug, evidenced by a significant decrease in related inflammatory markers, including high sensitivity C-reactive protein, matrix metalloproteinase- 9 , and NF- $\mathrm{KB}$ activity, especially at high doses, ie, $80 \mathrm{mg} /$ day. ${ }^{27}$ Aviram et al reported that atorvastatin did not affect oxidation of LDL in vitro, even at high concentrations. ${ }^{20}$ However, low pharmacological concentrations of specific hydroxylated metabolites of the drug 
demonstrated a very potent inhibitory effect on LDL, VLDL, and HDL oxidation, both in metal ion-dependent and metal ion-independent systems. The molecular structure of atorvastatin hydroxymetabolites enables them to act as electron donors and, hence, as potent antioxidants. ${ }^{20}$ Therefore, it may be proposed that even if the parent drug does not show antioxidant properties, its metabolites may have antioxidant activity in vivo. This may be the reason for the conflicting data generated by in vivo and ex vivo studies.

The scientific debate continues on how HDL exerts its protective effect against atherosclerosis. Until recently, the focus of attention was on the role of HDL in reverse cholesterol transport. The human serum paraoxonase 1 enzyme might be one of the ways in which HDL exerts its antiatherogenic action. ${ }^{28,29}$ Serum paraoxonase 1 is a $45 \mathrm{kDa}$ glycoprotein which is tightly bound to HDL subfractions containing apolipoprotein A-I and apolipoprotein $\mathrm{J}$ (clusterin). ${ }^{30}$ Paraoxonase 1 hydrolyzes aromatic carboxylic acid esters, organophosphates, carbamates, and lactones, and acts to protect LDL against oxidative modification, thereby exhibiting anti-atherogenic and anti-inflammatory effects. ${ }^{29}$ This proposal is based on the studies of Aviram and Mackness who showed that in vitro supplementation of human HDL or whole serum with purified paraoxonase 1 significantly inhibited $\mathrm{Cu}^{2+}$-induced lipoprotein oxidation in a concentration-dependent manner. ${ }^{28,31,32}$ The results of the present study show that an atherogenic diet results in a sharp decrease in paraoxonase activity, leading to loss of another guardian against oxidation and atherosclerosis. The inadequate paraoxonase activity seen in the atherogenic diet groups in this study probably contributes to the increased levels of oxidation markers (TBARS, oxidized LDL, LDLconjugated dienes). The low paraoxonase activity observed in the atherogenic diet groups is consistent with the results of other research. ${ }^{32}$

Loss of antioxidant paraoxonase activity from HDL or repressed expression of the enzyme may explain the decrease in paraoxonase activity seen with an atherogenic diet. In this study, although paraoxonase activity was studied, paraoxonase mass or expression was not assayed, so more detailed information will have to come from further studies.

Leitinger et al reported that an atherogenic diet resulted in the formation of oxidized phospholipids in livers of mice rendered genetically susceptible to diet-induced atherosclerosis. ${ }^{34}$ These oxidized phospholipids are believed to induce an acute-phase response which results in production of proinflammatory HDL susceptible to atherosclerosis. ${ }^{34}$ LDL-derived oxidized phospholipids were found to induce interleukin-6 in hepatocytes and to repress paraoxonase mRNA levels. In humans, paraoxonase 1 activity and serum HDL susceptibility to oxidation are reported to be inversely related in several groups of patients with increased risk for atherosclerosis, such as those with hypercholesterolemia, noninsulin-dependent diabetes, or vascular disease. . $2,35,36^{-36}$

Superoxide dismutase and catalase activity and malondialdehyde levels in aortic tissue gave us the chance to compare and evaluate oxidant status in aortic tissues from different groups (Figure 3). The results obtained coincide with the findings for LDL fractions and erythrocytes. Superoxide dismutase activity in the aortic tissue from the atherogenic diet group was significantly higher than in Group 1 controls. Superoxide dismutase activity in Group 4 rabbits receiving statin treatment with an atherogenic diet was as low as in Group 1 controls. Catalase activity in the same tissues did not show any statistically significant difference between groups, even though there was a slight increase of activity in the atherogenic diet group. These results can be explained as a collaborative interplay for defense against the rise of free oxygen radicals. ${ }^{18}$ Lipid peroxidation and aortic antioxidant defense mechanisms take action before the formation of gross lipid infiltration in the vessels of animals receiving an atherogenic diet, and some antioxidant mechanisms may act more prominently than others during this interplay. ${ }^{37}$ Other studies have also demonstrated significantly increased enzymatic activity and protein expression of superoxide dismutase in macrophage-rich atherosclerotic lesions in accordance with our data. ${ }^{38,39}$ The vessel wall being 100-fold richer than the other tissues for extracellular superoxide dismutase activity may also be the reason why the changes in the superoxide dismutase activity both in hypercholesterolemia and atorvastatin treatment were more expressive than the catalase activity observed in the aortic tissue. ${ }^{40}$ Malondialdehyde levels showed a two-fold increase in the atherogenic diet group in comparison with controls, and atorvastatin therapy lowered the levels of malondialdehyde to a point even lower than the control group. The aortic tissue probably was the best medium for atorvastatin to show its antioxidant and antiatherosclerotic effects, which are clearly shown by the oxidant status markers and histopathological data (Figure 4). The reason for this is probably because atherosclerosis is a complex and miscellaneous disease, and atorvastatin not only has a favorable influence on oxidation and lipid profiles, but also exhibits pleiotropic effects on inflammation, macrophage accumulation, and even the calcification phases the atherosclerotic plaque goes through. ${ }^{27,41-44}$ Reflecting the summation of all these effects 
of atorvastatin, aortic tissue was the best medium through which to observe the outcome of treatment.

Even though animal studies are very valuable, some mechanisms may differ from those in humans, and this may be one of the limitations of this study. Another limitation was that the animals did not undergo angiography. However, the histological data obtained at the end of the experiment could not have been obtained in human patients, and that is an advantage of the present study and similar studies carried out using animal models.

\section{Conclusion}

The benefit of atorvastatin therapy certainly appears to exceed the cholesterol-lowering effects of the statins, and this study provides evidence that atorvastatin has an anti-atherogenic effect in a primary prevention setting, not just by decreasing lipid levels, but also by suppressing oxidation of LDL. The beneficial effect of atorvastatin on oxidative status seems to be one of its most important benefits, ie, a preventative effect on plaque formation.

Despite the discussion on the widespread use of statins and at what point their use is essential, the present study shows that atorvastatin has a dramatic anti-atherosclerotic effect, and part of this effect seems to be due to the antioxidant features of the parent drug and/or its metabolites, favoring inhibition of LDL oxidation in addition to its other pleiotropic effects. We believe comprehending the entire spectrum of benefits associated with atorvastatin therapy would allow better therapeutic application and foster the early and appropriate use of a statin.

\section{Disclosure}

The authors report no conflicts of interest in this work.

\section{References}

1. Ross R. Atherosclerosis is an inflammatory disease. Am Heart J. 1999; 138(5 Pt 2):419-420.

2. Witztum JL, Steinberg D. The oxidative modification hypothesis of atherosclerosis: Does it hold for humans? Trends Cardiovasc Med. 2001; 11:93-102.

3. Hessler JR, Morel DW, Lewis LJ, Chisolm GM. Lipoprotein oxidation and lipoprotein-induced cytotoxicity. Arteriosclerosis. 1983;3:215-222.

4. Heinecke JW, Rosen H, Chait A. Iron and copper promote modification of low density lipoprotein by human arterial smooth muscle cells in culture. J Clin Invest. 1984;74:1890-1894.

5. Niki E, Noguchi N. Effects of antioxidants agains atherosclerosis. Mol Cell Biochem. 2002;234-235:19-25.

6. Holvoet P. Endothelial dysfunction, oxidation of low-density lipoprotein, and cardiovascular disease. Ther Apher. 1999;3:287-293.

7. Fuhrman B, Koren L, Volkova N, Keidar S, Hayek T, Aviram M. Atorvastatin therapy in hypercholesterolemic patients suppresses cellular uptake of oxidized-LDL by differentiating monocytes. Atherosclerosis. 2002;164:179-185.
8. Franzoni F, Quinones-Galvan A, Regoli F, Ferrannini E, Galetta F. A comparative study of the in vitro antioxidant activity of statins. Int J Cardiol. 2003;90:317-321.

9. Van Kampen EJ, Zijlstra WG. Determination of hemoglobin and its derivatives. Adv Clin Chem. 1965;8:141-187.

10. Sozmen EY, Sozmen B, Girgin F, et al. Antioxidant enzymes and paraoxonase show a co-activity in preserving low density lipoprotein from oxidation. Clin Exp Med. 2001;1:195-199.

11. Aebi H. Catalase in vitro. Methods Enzymol. 1984;105:121-126.

12. Taus M, Ferreti G, Dousset N, et al. Susceptibility to in vitro lipid peroxidation of low density lipoprotein and erythrocyte membranes from liver cirrhotic patients. Scand J Clin Lab Invest. 1994;54:147-153.

13. Lowry OH, Rosebrough MJ, Al F, Randall LJ. Protein measurement with the folin phenol reagent. J Biol Chem. 1951;193:265-275.

14. Betteridge DJ, Khan M. Statins and Coronary Artery Disease. London, UK: Science Press Ltd; 2001.

15. Bustos C, Henandez-Presa MA, Ortego M, et al. HMG-CoA reductase inhibition by atorvastatin reduces neointimal inflammation in a rabbit model of atherosclerosis. J Am Coll Cardiol. 1998;32:2057-2064.

16. Nawrocki JW, Weiss SR, Davidson MH. Reduction of LDL cholesterol by $25 \%$ to $60 \%$ in patients with primary hypercholeterolemia by atorvastatin, a new HMG-CoA reductase inhibitor. Arterioscler Thromb Vasc Biol. 1995;15:678-682.

17. Bertolini S, Bon GB, Campbell LM. Efficacy and safety of atorvastatin compared to pravastatin in patients with hypercholesterolemia. Atherosclerosis. 1997;79:1475-1481.

18. Erdincler DS, Seven A, Inci F, Beger T, Candan G. Lipid peroxidation and antioxidant status in experimental animals: Effect of aging and hypercholesterolemic diet. Clin Chim Acta. 1997;265:77-84.

19. Fukai T, Folz RJ, Landmesser U, Harrison DG. Extracellular superoxide dismutase and cardiovascular disease. Cardiovasc Res. 2002;55: 239-249.

20. Aviram M, Rosenblat M, Bisgainer CL, Newton RS. Atorvastatin and gemfibrozil metabolites, but not the parent drug, are potent antioxidant against lipoprotein oxidation. Atherosclerosis. 1998;138:271-280.

21. Davignon J, Jacob RF, Mason RP. The antioxidant effects of statins. Coron Artery Dis. 2004;15:251-258.

22. Wassman S, Laufs U, Muller K, et al. Cellular antioxidant effects of atorvastatin in in vitro and in vivo. Arterioscler Thromb Vasc Biol. 2002;22:300-305.

23. Oka H, Ikeda S, Koga S, Miyahara Y, Kohno S. Atorvastatin induces associated reductions in platelet P-selectin, oxidized low density lipoprotein, and interleukin-6 in patients with coronary artery disease. Heart Vessels. 2008;23:249-256.

24. Choi SH, Chae A, Miller E, et al. Relationship between biomarkers of oxidized low density lipoprotein, statin therapy, quantitative coronary angiography, and atheroma volume volume observations from the REVERSAL (Reversal of Atherosclerosis with Aggressive Lipid Lowering) study. J Am Coll Cardiol. 2008;52:24-32.

25. Orem C, Orem A, Uydu HA, Celik S, Erdol C, Kural BV. The effects of lipid lowering therapy on low density lipoprotein auto-antibodies: Relationship with low density lipoprotein oxidation and plasma total antioxidant staus. Coron Artery Dis. 2002;13:65-71.

26. Husseinn O, Schlesinger S, Rosenblat M, Keidar S, Aviram M. Reduced susceptibility of LDL to lipid peroxidation after fluvastatin therapy is associated with the hypocholesterolemic effect of the drug and its binding to the LDL. Atherosclerosis. 1997;128:11-18.

27. Singh U, Devaraj S, Jialal I, Siegel D. Comparison effect of atorvastatin (10 versus $80 \mathrm{mg}$ ) on biomarkers of inflammation and oxidative stress in subjects with metabolic syndrome. Am J Cardiol. 2008;102:321-325.

28. Mackness MI, Mackness B, Durrington PN, et al. Paraoxonase and coronary heart disease. Curr Opin Lipidol. 1998;9:319-324.

29. Aviram M. Does paraoxonase play a role in susceptibility to cardiovascular disease? Mol Med Today. 1999;5:381-386.

30. Kural BV, Orem C, Uydu HA, Alver A, Orem A. The effects of lipid lowering therapy on paraoxonase activities and their relationship with the oxidant-antioxidant system in patients with dislipidemia. Coron Artery Dis. 2004;15:277-283. 
31. Mackness B, Davies GK, Turkie W, et al. Paraoxonase status in coronary heart disease. Are activity and concentration more important than genotype? Arterioscler Thromb Vasc Biol. 2001;21:1451-1457.

32. Aviram M, Rosenblat M, Bisgaier CL, Newton RS, Primo-Parmo SL, La Du BN. Paraoxonase inhibits high density lipoprotein oxidation and preserves its functions. A possible peroxidative role for paraoxonase. J Clin Invest. 1998;101:1581-1590.

33. Shih DM, Gu L, Hama S, et al. Genetic dietary regulation of serum paraoxonase expression and its role in atherogenesis in a mouse model. J Clin Invest. 1996;97:1630-1639.

34. Leitinger N, Watson AD, Hama SY, et al. Role of group II secretory phospholipase A2 in atherosclerosis: 2. Potential involvement of biologically active oxidized phospholipids. Arterioscler Thromb Vasc Biol. 1999;19:1291-1298.

35. Heinecke JW, Lusis AJ. Paraoxonase gene polymorphism associated with coronary heart disease: Support for the oxidative damage hypothesis? Am J Hum Genet. 1998;62:20-24.

36. McTaggart F, Jones P. Effects of statins on high-density lipoprotens: A potential contribution to cardioascular benefit. Cardiovasc Drugs Ther. 2008;22:321-338.

37. Shull S, Heintz NH, Periasamy M, Manohar M, Janssen YM. Differential regulation of antioxidant enzymes in response to antioxidants. J Biol Chem. 1991;266:11180-11187.

38. Fukai T, Galis ZS, Meng XP, Parthasarathy S, Harrison DG. Vascular expression of extracellular superoxide dismutase in atherosclerosis. J Clin Invest. 1998;101:2101-2111.
39. Luoma JS, Stralin P, Marklund SL, Hiltunen TP, Sarkioja T, Yla-Herttuala S. Expression of extracellular SOD and iNOS in macrophages and smooth muscle cells in human and rabbit atherosclerotic lesions: colocalization with epitopes characteristic of oxidized LDL and peroxynitrite-modified proteins. Arterioscler Thromb Vasc Biol. 1998;18:157-167.

40. Stralin P, Kalsson K, Johansson BO, Markland SL. The intestitium of the human arterial wall contains very large amounts of extracellular superoxide dismutase. Arterioscler Thromb Vasc Biol. 1995;15:203-206.

41. Wang ZW, Liu XL, Zhong M, et al. Pleiotropic effects of atorvastatin on monocytes in atherosclerotic patients. J Clin Pharmacol. 2010; 50:311-319

42. Puato M, Faggin E, Rattazi M, et al. Atorvastatin reduces macrophage accumulation in atherosclerotic plaques. Stroke. 2010;41:1163-1168.

43. Rajamannan NM, Subramaniam M, Springett M, et al. Atorvastatin inhibits hypercholesterolemia-induced cellular proliferation and bone matrix production in the rabbit aortic valve. Circulation. 2002;105: 2660-2665.

44. Rajamannan NM, Subramaniam M, Caira F, Stock SR, Spelsberg TC. Atorvastatin inhibits hypercholesterolemia-induced calcification in the aortic valves via the Lrp5 receptor pathway. Circulation. 2005; 112 Suppl I:I229-I234.
Vascular Health and Risk Management

\section{Publish your work in this journal}

Vascular Health and Risk Management is an international, peerreviewed journal of therapeutics and risk management, focusing on concise rapid reporting of clinical studies on the processes involved in the maintenance of vascular health; the monitoring, prevention and treatment of vascular disease and its sequelae; and the involvement of

\section{Dovepress}

metabolic disorders, particularly diabetes. This journal is indexed on PubMed Central and MedLine. The manuscript management system is completely online and includes a very quick and fair peer-review system, which is all easy to use. Visit http://www.dovepress.com/ testimonials.php to read real quotes from published authors 